\title{
Intestinal carcinoid tumours in a father and daughter
}

\author{
Tuya Pal MD ${ }^{1}$, Alexander Liede MSc ${ }^{1}$, Margot Mitchell MSW1', Alain Calender PhD², \\ Steven A Narod MD ${ }^{1}$
}

T Pal, A Liede, M Mitchell, A Calender, SA Narod. Intestinal carcinoid tumours in a father and daughter. Can J Gastroenterol 2001;15(6):405-409. Familial cases of carcinoid tumours that are not associated with any known syndrome or disease are extremely rare. All cases reported in the world literature have involved carcinoid tumours of the gastrointestinal tract. Two cases of carcinoid tumours of the small intestine in a father and daughter are presented. Laboratory analyses did not support the hypothesis that the occurrence of carcinoid tumours in this family is a variant of the multiple endocrine neoplasia type 1 syndrome. A review of the literature on familial occurrence of intestinal carcinoid tumours in the absence of any other known carcinoid tumour-predisposing genetic syndrome is provided.

Key Words: Carcinoid tumours; Small intestine

\section{Tel père, telle fille : tumeurs carcinoïdes de l'intestin}

RÉSUMÉ : Les cas familiaux de tumeurs carcinoïdes non associées à des maladies ou à des syndromes connus sont extrêmement rares. Tous les cas signalés dans la documentation scientifique mondiale font état de tumeurs carcinoïdes du tractus gastro-intestinal. Voici deux cas de tumeur carcinoïde du petit intestin : l'un chez le père, l'autre chez la fille. Les analyses de laboratoire ont écarté l'hypothèse de la variante de l'adénomatose polyendocrinienne de type I pour expliquer l'apparition des tumeurs carcinoïdes dans la famille. Suit une revue de la documentation scientifique sur l'apparition des tumeurs carcinoïdes de l'intestin dans des familles en l'absence de tout autre syndrome génétique connu de prédisposition aux tumeurs carcinoïdes.
Cast arcinoid tumours are derived from the neuroendocrine system and are a morphologically distinct class of tumours. They store 5-hydroxytryptophan and a range of other peptides. Approximately $85 \%$ of carcinoid tumours develop in the gastrointestinal tract; the most frequent location is the appendix, followed by the rectum and the ileum (1). They usually occur sporadically, but have also been described as part of a familial tumour complex (2-9).

Multiple cases of carcinoid tumours have been reported in hereditary cancer susceptibility syndromes, most notably, multiple endocrine neoplasia (MEN) type 1, and occasionally MEN2 and neurofibromatosis type 1 (NF1). A case has been reported of carcinoid tumours coexisting with familial adenomatous polyposis (FAP) in a single patient (10).

MEN1 is an autosomal genetic disorder characterized by the familial association of parathyroid, pancreatic islet and pituitary tumours (11). Hyperparathyroidism is the most common manifestation of MEN1 and is present in $90 \%$ to $100 \%$ of these patients. Carcinoid tumours are an uncommon manifestation of MEN1 (12,13).

The MEN1 gene has been localized to the long arm of chromosome 11 (11q13) (14-16) and encodes a novel protein consisting of 610 amino acids, referred to as MENIN $(17,18)$. When the specific mutation is not known in a MEN1 family, the optimal screening test for the identification of the gene carrier state is an albumin-adjusted or ionized serum calcium measurement, which may be supplemented by a serum parathyroid hormone measurement $(19,20)$.

Carcinoid tumours have also been seen in individuals with MEN2 (13), although even more rarely than in patients with MEN1. MEN2 is a genetically heterogeneous

${ }^{1}$ Centre for Research in Women's Health, Sunnybrook and Women's College Health Sciences Centre, Toronto, Ontario, ${ }^{2}$ Genetic Unit, Pavillon E, Hôpital Edouard Herriot, Place d'Arsonval, Lyon, France

Correspondence: Dr T Pal, Centre for Research in Women's Health, Sunnybrook and Women's College Health Sciences Centre,

790 Bay Street, 750A, Toronto, Ontario M5G 1N8. Telephone 416-351-3765, fax 416-351-3767, e-mail tuya.pa@uhn.on.ca

Received for publication May 16, 2000. Accepted August 8, 2000 


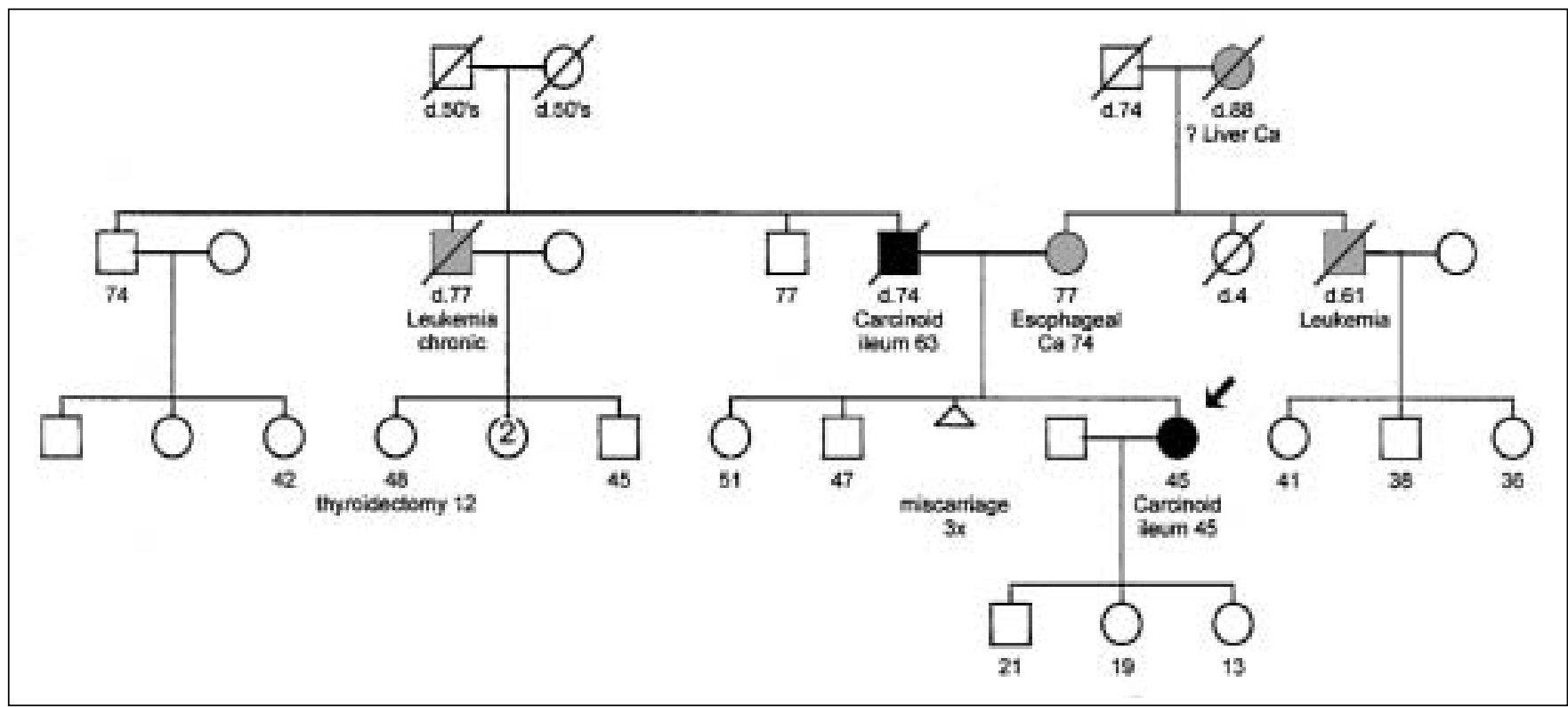

Figure 1) Pedigree of a carcinoid family. Note the occurrence of carcinoid tumours in the proband and her father. The proband is indicated by an arrow. Black shaded symbols indicate a diagnosis of intestinal carcinoid tumour, grey shaded symbols indicate another diagnosis of cancer (Ca). Ages are shown directly below the symbol with "d." preceding age at death. Cancer diagnoses are followed by the age at diagnosis

autosomal condition further subcategorized into two variants called MEN2A and MEN2B. MEN2A is characterized by the familial association of medullary thyroid cancer, pheochromocytoma and parathyroid adenoma; MEN2B is also characterized by this tumour spectrum and its hallmark finding of characteristic mucosal neuromas on the distal portion of the tongue, on the lips and subconjunctival areas, and throughout the gastrointestinal tract. The diagnosis of MEN2 is made on a clinical basis.

NF1 is a third autosomal dominant inherited condition in which carcinoid tumours have been described $(21,22)$. NF1 is characterized by a combination of dermatological, ophthalmological and skeletal findings, and the diagnosis is made on a clinical basis by standardized National Institutes of Health Diagnostic Criteria (23).

A case has been reported of recurrent carcinoid tumours in association with duodenal adenomas in a patient with FAP (10). This finding may be a chance occurrence or a true association. FAP is an autosomal dominant, colon cancer-predisposing condition, characterized by more than 100 adenomatous polyps in the gastrointestinal tract that progress to colorectal carcinoma. The diagnosis of FAP is made on a clinical basis in conjunction with a complete family history.

The carcinoid syndrome consists of clinical symptoms including flushing, diarrhea, abdominal pain and congestive heart failure from carcinoid heart disease (the spectrum of which includes valvular heart disease, myocardial metastases and pericardial effusion). Although the exact pathogenesis of the symptoms remains unknown, some symptoms are related to the hormonal production of these tumours. Despite improved diagnostic methods, the recognition of the clinical syndrome, related to hormone production by carcinoids, is difficult. In the majority of cases of carcinoid syndrome, metastatic carcinoid tumours of the small intestine are present (24).

The case of a father and daughter with carcinoid tumours of the small intestine, both of whom presented with the carcinoid syndrome, is presented (Figure 1). Germline DNA was analyzed for MEN1 mutations and tumour block pathology was reviewed.

\section{CASE PRESENTATIONS}

Case 1: A 45-year-old woman was found to have a carcinoid tumour of the ileocecal region in 1996 (proband in Figure 1). She had a 10-year history of gastrointestinal problems and flushing. Her gastrointestinal symptoms included diarrhea, bloating, postprandial nausea and vomiting, excessive flatus production and abdominal discomfort. Results from ultrasound studies of the gastrointestinal tract suggested a right lower quadrant mass with possible intussusception. Computed tomography scan confirmed the presence of a lower quadrant small bowel intussusception at the ileocolic junction. Laparotomy in December of 1996 revealed a $3 \mathrm{~cm}$ carcinoid tumour of the ileocecal region with extension through full thickness of the bowel wall into the serosa and pericolic fat. Two regional lymph nodes were positive for metastatic tumour, and perineural involvement was described. The resection margins were negative, and no evidence of distant spread of disease was present. The patient had normal serum ionized calcium and normal parathyroid hormone levels. The patient is currently well. She had none of the clinical stigmata associated with MEN2 or NF1. There were no findings suggestive of FAP.

Case 2: The father of the proband presented at age 63 years, after several years of lower back discomfort and 
TABLE 1

Published reports of familial carcinoid syndrome in the absence of any known carcinoid-predisposing genetic syndromes

\begin{tabular}{|c|c|c|c|c|c|}
\hline Report & $\begin{array}{l}\text { Number } \\
\text { of families }\end{array}$ & $\begin{array}{c}\text { Number of } \\
\text { affected members }\end{array}$ & Relation & $\begin{array}{l}\text { Tumour } \\
\text { location }\end{array}$ & Clinical manifestations \\
\hline Eschbach and Rinaldo (2) & 1 & 2 & Brother and sister & Ileum & Serum calcium (normal) \\
\hline Anderson (3) & 1 & 2 & Father and daughter & Appendix & No tests reported \\
\hline Moertel and Dockerty (4) & 1 & 3 & Sister, brother and niece & Ileum & No tests reported \\
\hline \multirow[t]{2}{*}{ Wale et al (5) } & 2 & 2 & Sisters & Ileocecum & No tests reported \\
\hline & & 2 & Sister and brother & Ileum & No tests reported \\
\hline Yeatman et al (6) & 1 & 3 & Father and two sons & Duodenum & $\begin{array}{l}\text { Serum calcium, phosphorus, } \\
\text { PTH and calcitonin (normal) }\end{array}$ \\
\hline Lengyel et al (7) & 1 & 2 & Father and daughter & Jejunum & No test reported \\
\hline Yoshikane et al (8) & 1 & 2 & Two sisters & Stomach & Serum gastrin (elevated)* \\
\hline Babovic-Vuksanovic et al (9) & 9 & 19 & All first-degree $\quad S m$ & ll bowel and colon & No tests reported \\
\hline Present case & 1 & 2 & Father and daughter & Ileum & Testing negative ${ }^{\dagger}$ \\
\hline
\end{tabular}

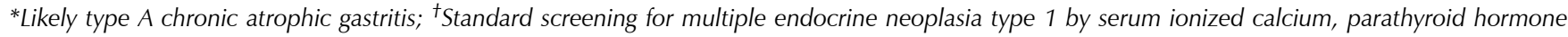
(PTH), gastrin and prolactin

chronic gastrointestinal problems with diarrhea and flushing. On physical examination, he had infra-umbilical tenderness and a palpable mass. Laparotomy was done in mid-1976, at which time the primary tumour was resected. The pathology report revealed an infiltrating carcinoid tumour of Meckel's diverticulum and the wall of the ileum. Metastatic disease was present in the liver and mesenteric nodes. He was given several courses of chemotherapy with 5-fluorouracil; the last treatment was given in November 1984. Following resection of the tumour, he did well at home aside from daily episodes of flushing and a mild degree of diarrhea, controlled with medication. The cardiac manifestations of his carcinoid tumour consisted of damage to his tricuspid valve resulting in mild ankle swelling. In mid-1987, at the age of 74 years, he started to develop increasing weight loss, fatigue, anorexia, increased abdominal girth with ascites and bilateral pleural effusions. He died in December 1987 at the age of 74 years of metastatic disease. Laboratory analysis: The pathology of paraffin-embedded tumour blocks was reviewed for both the proband and her father. There was concern that this family may be a MEN1 variant because multiple carcinoid tumours in a family have been described for this syndrome (25). The proband and her two siblings were screened with the standard blood testing regimen for MEN1, including serum ionized calcium, parathyroid hormone, gastrin and prolactin, all of which were normal. These tests detect over $90 \%$ of MEN1 carriers after age 40 years (26).

To investigate further the possibility of MEN1, mutation analysis was performed on the proband's DNA with heteroduplex analysis and full gene sequencing as previously reported (27). Mutations in $75 \%$ to $80 \%$ of patients with MEN1 are detected using this method (28).

\section{RESULTS}

The pathologic tumour material from each of the patients was reviewed, and typical carcinoid histology was confirmed. No germline MEN1 mutations were detected in the proband by heteroduplex analysis and full gene sequencing. Nevertheless, this analysis did not exclude a mutation in the uncharacterized $5^{\prime}$ regulatory region of the MEN1 gene nor the presence of a large germline deletion as reported by Kishi et al (29) who used quantitative polymerase chain reaction methods.

\section{DISCUSSION}

There have been a limited number of families reported with familial carcinoid tumours in the absence of any other known carcinoid tumour-predisposing genetic syndrome (Table 1). The carcinoid tumours in all affected individuals in these families have been limited to the gastrointestinal tract. Eschbach and Rinaldo (2) described the first familial case in a brother and sister who had metastatic carcinoid tumours of the ileum. The ionized calcium in the proband was normal. Anderson (3) described a father and daughter who both had nonmetastasizing carcinoid tumours of the appendix discovered incidentally at appendectomy with no evidence of carcinoid syndrome. Moertel and Dockerty (4) described three cases of multicentric and metastasizing carcinoid tumours originating in the terminal ileum in two generations of a family. The patients all had evidence of carcinoid syndrome. Wale et al (5) described two family groups with familial carcinoid tumours and evidence of carcinoid syndrome. Their first family consisted of two sisters with metastatic carcinoid tumours in the ileocecal region; the other family consisted of a sister and brother with metastatic carcinoid tumour in the terminal ileum. Yeatman et al (6) reported a father and two sons with proximal duodenal carcinoid tumours. Lengyel et al (7) described a father and daughter with intestinal carcinoid tumours. Recently, Yoshikane et al (8) described the familial occurrence of gastric carcinoid tumours associated with type A chronic atrophic gastritis in two sisters. There was an elevation in serum gastrin in both sisters and the father. Because gastric carcinoid tumours can arise in the presence of type A chronic atrophic gastritis (the most common type 
of gastric carcinoid), the hereditary factor in this family may be a predisposition to chronic atrophic gastritis. The gastric carcinoids may be a secondary finding.

In a more recent chart review conducted at the Mayo Clinic on patients with malignant carcinoid tumours of the gastrointestinal tract diagnosed between 1988 and 1996, nine of 245 patients (3.7\%) had at least one first-degree relative with the same malignancy; one patient had two affected relatives (9). Of the 10 relatives with carcinoid tumours, five had tumours located in the small bowel, and two in the colon, and information about the location was unavailable in three. The authors described the rate of carcinoid tumour in first-degree relatives of probands as higher than expected $(\mathrm{P}<0.0001)$ based on the surveillance, epidemiology and end result population data. It was estimated that the cumulative probability of a first-degree relative developing a carcinoid tumour is $1.5 \%$ to age 80 years (9). Neither patients with carcinoid tumours nor their firstdegree relatives had an increased incidence of other malignancies according to this study.

The presence of small intestinal carcinoid tumours in two generations is strongly suggestive of a genetic etiology. Possibilities include a variant of a known carcinoid-predisposing genetic condition (ie, MEN1, MEN2 or NF1) or a new syndrome of familial carcinoid tumours of the gastrointestinal tract. The likelihood that the family described in the present case is a MEN1 variant is low. The diagnosis of MEN1 is based on a family history of pituitary, parathyroid and pancreatic islet cell tumours, and none of these characteristics were present in the family. Hyperparathyroidism, the most commonly associated manifestation of MEN1, was also investigated and found not to be present in the proband and her siblings. The age-related penetrance of hyperparathyroidism, based on serum calcium and prolactin, exceeds $90 \%$ by age 45 years (26). These negative clinical findings reduce the likelihood of MEN1 involvement in this family. Additionally, DNA analysis with full gene sequencing did not identify any mutations in the MEN1 gene.

Previously reported cases (2-9) were published after the recognition of the MEN1 syndrome (30), did not have any

\section{REFERENCES}

1. Peckham M, Pinedo HM, Veronesi U. Oxford Textbook of Oncology. New York: Oxford University Press, 1995.

2. Eschbach JW, Rinaldo JA. Metastatic carcinoid - a familial occurrence. Ann Intern Med 1962;57:647-50.

3. Anderson RE. A familial instance of appendiceal carcinoid. Am J Surg 1966;111:738-40.

4. Moertel CG, Dockerty MB. Familial occurence of metastasizing carcinoid tumors. Ann Intern Med 1973;78:389-90.

5. Wale RJ, Williams JA, Beeley AH, Hughes ESR. Familial occurrence in carcinoid tumors. Aust NZ J Surg 1983;53:325-8.

6. Yeatman TJ, Sharp JV, Kimura AK. Can susceptibility to carcinoid tumors be inherited? Cancer 1989;63:390-3.

7. Lengyel G, Karteszi M, Vallent K, et al. Familial occurrence of carcinoid of the small intestine. Orv Hetil 1989;130:573-5.

8. Yoshikane H, Nishimura K, Hidano H. Familial occurrence of gastric carcinoid tumors associated with type A chronic atrophic gastritis. Am J Gastroenterol 1998;93:833-4.

9. Babovic-Vuksanovic D, Constantinou CL, Rubin J, Rowland CM, Schaid DJ, Karnes PS. Familial occurrence of carcinoid tumors and
MEN1-associated tumours and were not suggestive of MEN1 based on the clinical information available in the reports. As previously mentioned, in rare instances carcinoid tumours occur in MEN2 (13), an autosomal dominant syndrome characterized by the familial association of medullary thyroid cancer, pheochromocytoma, and parathyroid hyperplasia or adenomatosis. Mutations in the RET gene are associated with MEN2 $(31,32)$, and mutational analysis is a useful test for detection of the condition (33) when clinically indicated. Based on the absence of MEN2-associated tumours and hyperparathyroidism, it was not thought that mutational analysis of the RET protooncogene was indicated in the present proband. Carcinoid tumours have also rarely been described in NF1 $(21,22)$. There was no evidence to support the clinical diagnosis of NF1 as the etiology of the carcinoid tumour in the present proband. More recently, a patient with FAP and recurrent carcinoid tumours located at the bases of duodenal adenomas was reported (10). This finding may represent a true association between FAP and recurrent carcinoid tumours, or be a chance occurrence. There was no evidence of FAP in the present proband or any family history suggestive of the condition.

There is evidence to support that these cases of familial carcinoid tumours of the gastrointestinal tract (2-9) represent a new genetic entity. Diagnostic criteria for this new syndrome should include exclusion of MEN1 through screening for hyperparathyroidism and any MEN1-associated tumours in the family. A detailed family history and complete physical examination should be performed to rule out MEN2, NF1 and possibly FAP.

ACKNOWLEDGEMENTS: We thank Mrs J Salandre for her technical assistance in MEN1 gene analysis. Genetic studies performed have been supported by grants from Hospices Civils de Lyon, referenced PHRC 97-048 and from the Institut national de la Santé et de la Recherche Medicale (INSERM), referenced CAR 494017. Dr A Liede's doctoral studies are supported by the Medical Research Council of Canada.

association with other malignant neoplasms. Cancer Epidemiol Biomarkers Prev 1999;8:715-9.

10. July LV, Northcott KA, Yoshida EM, Carr DM, Owen DA. Coexisting carcinoid tumors in familial adenomatous polyposis - associated upper intestinal adenomas. Am J Gastroenterol 1999;94:1991-4.

11. Anderson DK. What's new in general surgery? Ann Surg 1989;210:685.

12. Eberle F, Grun R. Multiple endocrine neoplasia, type 1 (MEN 1). Ergeb Inn Med Kinderheilkd 1981;46:76-149.

13. Duh Q, Hybarger CP, Gelst R, et al. Carcinoids associated with multiple endocrine neoplasia syndromes. Am J Surg 1987;154:142-8.

14. Bale SJ, Bale AE, Stewart K, et al. Linkage analysis of multiple endocrine neoplasia type 1 with INT2 and other markers on chromosome 11. Genomics 1989;4:320-2.

15. Larsson C, Skogseid B, Nakamura Y, et al. Multiple endocrine neoplasia type 1 gene maps to chromosome 11 and is lost in insulinoma. Nature 1988;332:85-7.

16. Thakker RV, Wooding C, Pang JT, et al. Linkage analysis of 7 polymorphic markers at chromosome $11 \mathrm{p} 11.2-11 \mathrm{p} 13$ in 27 multiple endocrine neoplasia type 1 families. Ann Hum Genet 1989;57:17-25. 
17. Chandrasekharappa SC, Guru SC, Manickam P, et al. Positional cloning of the gene for multiple endocrine neoplasia type 1 . Science 1997;276:404-7.

18. MEN1 Consortium. Definition of the minimal MEN1 candidate area based on a $5 \mathrm{MB}$ integrated map of proximal 11q13. Genomics 1996;37:354-65.

19. Marx SJ, Vinik AI, Santen RJ, et al. Multiple endocrine neoplasia type 1: assessment of laboratory tests to screen for the gene in a large kindred. Medicine 1986;65:226-41.

20. Benson L, Ljunghall S, Akerstrom G, et al. Hyperparathyroidism presenting as the first lesion in multiple endocrine neoplasia type 1 Am J Med 1987;82:731-7.

21. Griffiths DFR, Williams GT, Williams ED. Duodenal carcinoid tumors, phaeochromocytoma and neurofibromatosis: islet cell tumor, phaeochromocytoma and the von Hippel-Lindau complex: two distinctive neuroendocrine syndromes. Q J Med 1987;245:769-82.

22. Hough DR, Chan A, Davidson H. Von Recklinghausen's disease associated with gastrointestinal carcinoid tumors. Cancer 1983;51:2206-8.

23. Stumpf DA, Alksne JF, Annegers JF, et al. Neurofibromatosis: conference statement. Arch Neurol 1988;45:575-8.

24. Kvols LK. Metastatic carcinoid tumors and the malignant carcinoid syndrome. Ann NY Acad Sci 1994;733:464-70.
25. Sugimoto K, Oosawa S, Furuta T, et al. Multiple endocrine neoplasia type 1 accompanied by duodenal carcinoid tumors and hypergastrinemia: a familial case. Intern Med 1995;34:649-53.

26. Trump D, Farren B, Wooding C, et al. Clinical studies of multiple endocrine neoplasia type 1 (MEN1). Q J Med 1996:653-69.

27. Giraud S, Zhang CX, Serova-Sinilnikova O, et al. Germ-line mutation analysis in patients with multiple endocrine neoplasia type 1 and related disorders. Am J Hum Genet 1998;63:455-67.

28. Bassett JHD, Forbes SA, Pannett AAJ, et al. Characterization of mutations in patients with multiple endocrine neoplasia type 1 . Am J Hum Genet 1998;62:232-44.

29. Kishi M, Tsukada T, Shimizu S, et al. A large germline deletion of the MEN1 gene in a family with multiple endocrine neoplasia type 1 . Jpn J Cancer Res 1998;89:1-5.

30. Wermer P. Genetic aspects of adenomatosis of endocrine glands. Am J Med 1954:16:363-7.

31. Mulligan LM, Kwok JB, Healey CS, et al. Germ-line mutations of the RET proto-oncogene in multiple endocrine neoplasia type $2 \mathrm{~A}$. Nature 1993;363:458-60.

32. Phay JE, Moley JF, Lairmore TC. Multiple endocrine neoplasias. Sem Surg Oncol 2000;18:324-32.

33. Noll WW. Utility of RET mutation analysis in multiple endocrine neoplasia type 2. Arch Pathol Lab Med 1999;123:1047-9. 


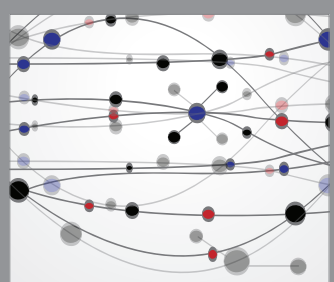

The Scientific World Journal
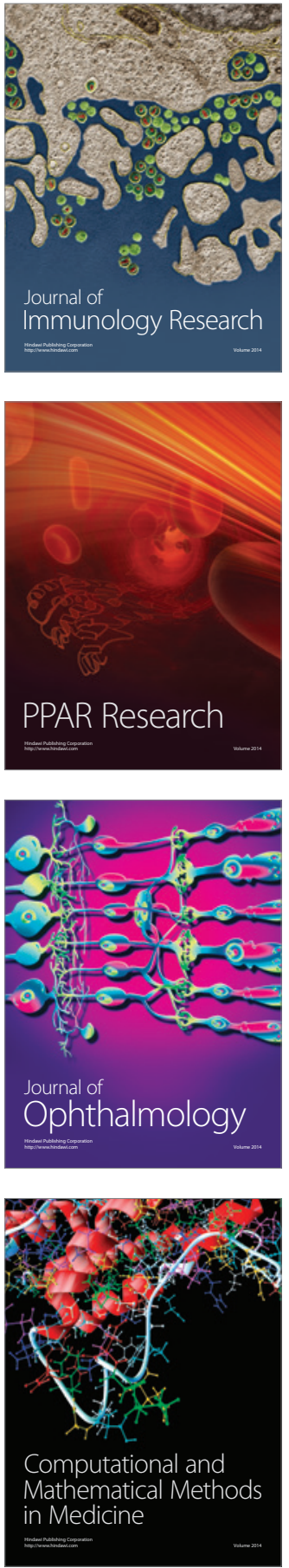

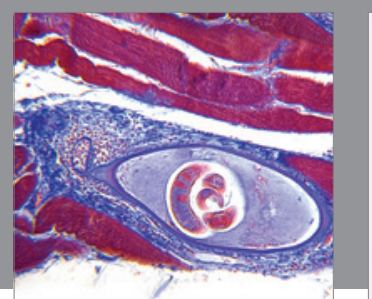

Gastroenterology Research and Practice

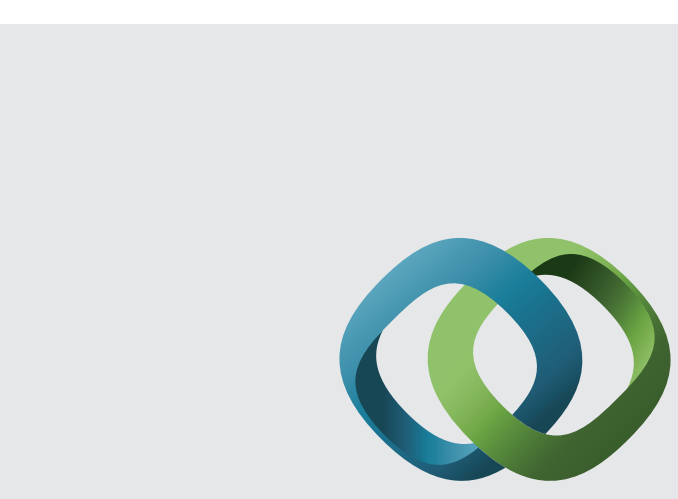

\section{Hindawi}

Submit your manuscripts at

http://www.hindawi.com
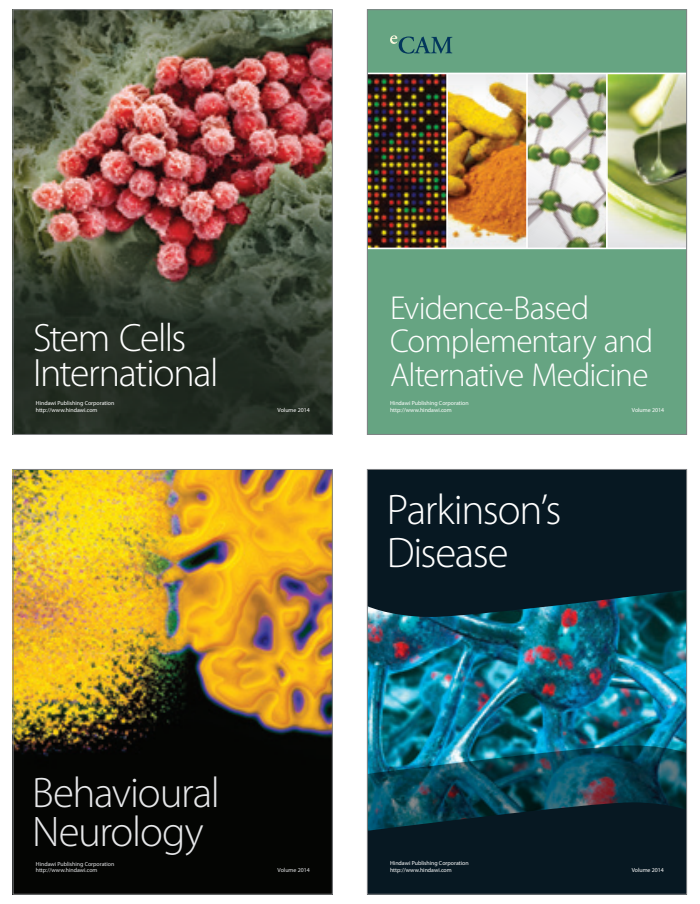
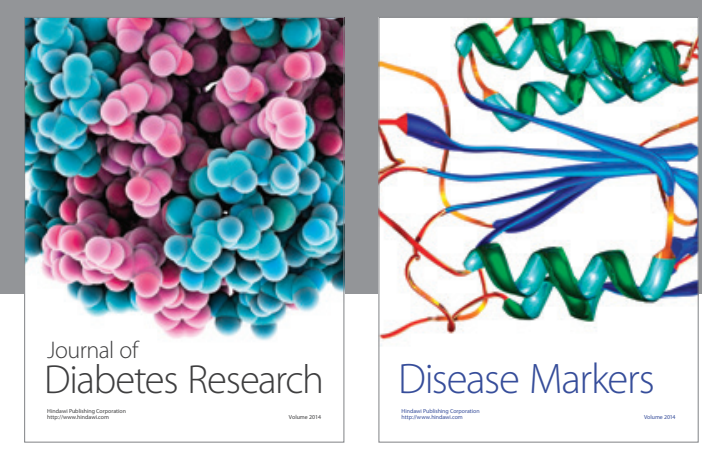

Disease Markers
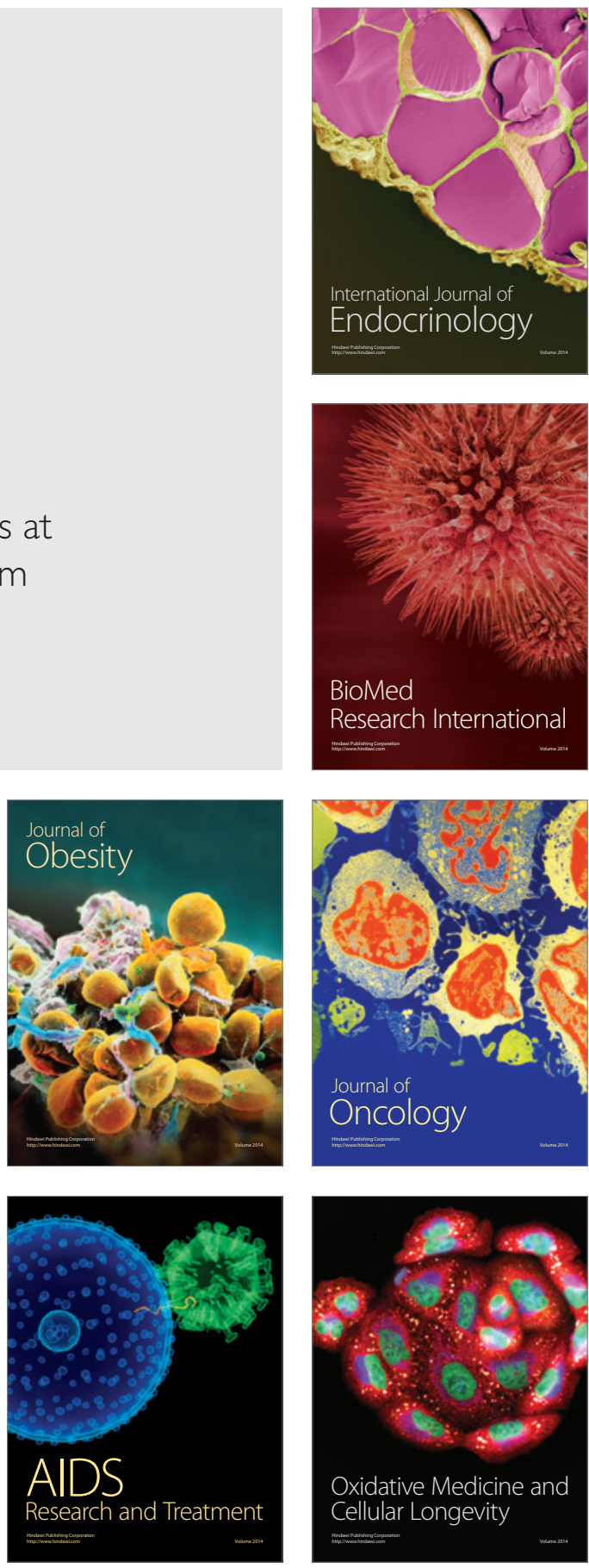